\title{
Santalum album as a Specialty Seed Oil Source: A Preliminary Study
}

\author{
Subasinghe S.M.C.U.P. ${ }^{*}$ and Hettiarachchi D.S. ${ }^{2}$ \\ ${ }^{I}$ Department of Forestry and Environmental Science,University of Sri Jayewardenepura, Sri Lanka \\ ${ }^{2}$ Wescorp Agarwood, Wescorp Group of Companies, Western Australia \\ *upuls@sjp.ac.lk
}

\begin{abstract}
Sandalwood is a commercially and culturally important plant species belongs to Family Santalaceae. Genus Santalum consists of 16 species where eight of them are commercially used as sources of valuable stem oil. In recent times sandalwood has been cultivated as an agroforesty crop to provide a sustainable solution to global sandalwood demand.

Apart from stem oil, Western Australian scientists and industry identified sandalwood seed oil as a potential income for the plantation sector during the long crop cycle. Seed oils are increasingly used for cosmetic, nutritional and medicinal product, thus creating a niche for specialty oils. Further, an early study revealed that seeds of certain sandalwood species contain a rare acetylenic fatty acid in its lipid content, known as ximenynic acid. Further studies into Santalum spicatum (Australian sandalwood) found that the ximenynic acid has antiinflammatory and vasodilator effects. This fatty acid is also reported in S. album, but a systematic study to evaluate its lipid content and fatty acid profile has not been reported.
\end{abstract}

Therefore this study is a preliminary attempt to identify and quantify the seed parameters, lipid content and the fatty acid profile of $S$. album grown in plantations and home gardens of Sri Lanka. Trees growing in two different vegetations, i.e., a 4-year old plantation at Beragala (BG) and mature trees naturally growing in homegardens at Welimada (WM) were selected for this purpose. 100 seeds were collected from May to June 2015 and coats were removed and the oil of the kernel was collected by solvent extraction. The key constituents were detected using GCMS methods.

According to the results, the average seed diameter $(5.57 \pm 0.05 \mathrm{~mm})$ was smaller in WM trees of homegardens than the seeds of BG $(6.26 \pm 0.03 \mathrm{~mm})$ though the seed oil content was much higher $(40.34 \pm 5.27 \%)$ than BG $(27.5 \pm 6.85 \%)$. The ximenynic acid content of BG and WM were $94.67 \pm 1.03 \%$ and $91.17 \pm 0.65 \%$ respectively and those were not statistically significant. There were no significant differences of palmitic acid $(\mathrm{BG}=0.31 \%$; $\mathrm{WM}=0.36 \%)$, palmitolenic acid $(\mathrm{BG}=0.10 \% ; \mathrm{WM}=0.13 \%)$; stearic acid $(\mathrm{BG}=0.42 \% ; \mathrm{WM}=0.35 \%)$; linoleic acid $(\mathrm{BG}=0.38 \% ; \mathrm{WM}=0.26 \%)$ and linolenic acid $(\mathrm{BG}=0.13 \% ; \mathrm{WM}=0.12 \%)$. However, significant differences were found for oleic acid $(\mathrm{BG}=2.96 \% ; \mathrm{WM}=6.29 \%)$ and steroic acid $(\mathrm{BG}=0.56 \%$; $\mathrm{WM}=1.05 \%)$.

Further studies are currently under way to identify the variations of the above parameters covering wider geographical areas and different plantation types. Based on these results Sri Lankan sandalwood growers could be benefitted by providing sandalwood seeds as a source of specialty seed oil.

Keywords: Santalum album, Seed oil, Ximenynic acid, Acetylenic fatty acid

Proceedings of the International Forestry and Environment Symposium 2016, Department of Forestry and Environmental Science, University of Sri Jayewardenepura, Sri Lanka. 